\title{
Research Paper: The Effect of Aspirin and Enoxapa- rin on the Prevention of Venous Thromboembolism in Patients With Ankle Sprain and Cast Immobiliza- tion: A Randomized Clinical Trial
}

\author{
Mehran Razavipour $^{1}$ (D, Salman Ghaffari' ${ }^{1}$ (D), Mehdi Mohebi ${ }^{1}$ (D), Shayan Amjadi ${ }^{*}$ (D)
}

1. Department of Orthopedics, Orthopedic Research Center, Mazandaran University of Medical Sciences, Sari, Iran.

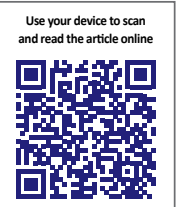

Ctition Razavipour M, Ghaffari S, Mohebi M, Amjadi Sh. The Effect of Aspirin and Enoxaparin on the Prevention of Venous Thromboembolism in Patients With Ankle Sprain and Cast Immobilization: A Randomized Clinical Trial. Journal of Research in Orthopedic Science. 2021; 8(1):9-16. http://dx.doi.org/10.32598/JROSJ.8.1.703.2

http://dx.doi.org/10.32598/JROSJ.8.1.703.2

Article info:

Received: 23 Nov 2020

Revised: 10 Dec 2020

Accepted: 10 Jan 2021

Available Online: 01 February 202

Keywords:

Ankle sprains, Venous thromboembolism, Immobilization, Aspirin, Enoxaparin

\begin{abstract}
A B S T RA C T
Background: The incidence of Venous Thromboembolism (VTE) and its prophylaxis in patients with an ankle injury and cast immobilization are controversial.

Objectives: This study aimed to investigate the effect of aspirin and enoxaparin on VTE prevention in patients with an ankle sprain and cast immobilization.

Methods: In a double-blind, randomized clinical trial, 90 eligible patients were divided into three groups: patients who did not receive the drugs (the control group), patients who received aspirin ( $325 \mathrm{mg} / \mathrm{d}$ ) for 3 weeks (the ASA group), and patients who received enoxaparin ( $40 \mathrm{mg} / \mathrm{d}$ subcutaneously) for 3 weeks (the enoxaparin group). After 3 weeks, the plaster was opened, and the D-dimer level was measured if there was a VTE symptom during the study. Otherwise, at the end of the study, the bilateral lower-limb Complete Compression Ultrasonography (CCUS) and color Doppler ultrasound were used to image the lower limb venous system.

Results: Sixty-eight patients completed the study. The Mean \pm SD values of D-dimer in the control, ASA, and enoxaparin groups were $0.33(0.47) \mu \mathrm{g} / \mathrm{dL}$ (Median=0.18 $\mu \mathrm{g} / \mathrm{dL}), 0.32(0.14)$ $\mu \mathrm{g} / \mathrm{dL}$ (Median=0.3 $\mu \mathrm{g} / \mathrm{dL}$ ) and $0.32(0.25) \mu \mathrm{g} / \mathrm{dL}$ (Median=0.21 $\mu \mathrm{g} / \mathrm{dL})$, respectively $(\mathrm{P}>0.05)$. The positive D-dimer was seen in 2 patients $(8 \%)$ of the control group, 2 patients $(8.3 \%)$ of the ASA group, and 2 patients $(10.5 \%)$ of the enoxaparin group $(\mathrm{P}>0.05)$. The color Doppler ultrasound was negative in all patients.

Conclusion: Because none of the 68 patients in the current study developed VTE during our 30 days follow-up period, it seems that prophylaxis treatment is unnecessary in patients with an ankle sprain and cast immobilization. Further studies on more patients with a longer period of follow-up are recommended.
\end{abstract}

* Corresponding Author:

Shayan Amjadi, PhD.

Address: Department of Orthopedics, Mazandaran University of Medical Sciences, Sari, Iran

Phone: +98 (912) 7018377

E-mail: shayanamjadi@yahoo.com 


\section{Introduction}

he overall incidence of lower limb injuries is increasing due to population growth rates and possibly increased participation in sports activities [1]. Immobilization is the main management of isolated below-knee injuries, including fractures, ligament or cartilage injuries, and ankle sprain. This management increases the risk of Deep Vein Thrombosis (DVP) [2]. According to the literature, below-knee cast immobilization is strongly associated with thrombosis [3]. The prevalence of venous thromboembolism (VTE) has been reported to vary from $1.1 \%$ to $20 \%$ in patients with below-knee cast immobilization [4-9]. VTE significantly increases morbidity (including post-thrombotic syndrome and pulmonary hypertension) and mortality rate $[8,9]$.

Regarding the variable incidence of VTE after belowknee cast immobilization, the use of prophylaxis is controversial. American College of Chest Physicians Guidelines does not suggest pharmacological thromboprophylaxis in these patients [10]. In contrast, national guidelines or expert recommendations published in several Western European countries recommend thromboprophylaxis, at least in certain patients with other VTE risk factors [11-19].

Enoxaparin is Low Molecular Weight Heparin (LMWH) and widely used to prevent VTE in patients with lower limb injury and immobilization cast [2022]. However, enoxaparin has some serious side effects, such as major bleeding episodes and Heparin-Induced Thrombocytopenia (HIT) [23]. These side effects limit the use of enoxaparin in low-risk outpatients $[12,24]$.

Aspirin is a Nonsteroidal Anti-Inflammatory Drug (NSAID) and suppresses the normal function of platelets. The role of aspirin in the primary prevention of VTE has been evaluated in various studies [25-28]. Recently, some orthopedic research suggested that aspirin can reduce the VTE rate [29-31]. Also, aspirin is a simple, inexpensive, and widely available treatment and can be safely used in outpatients [32].

Because the type, dose, or duration of thromboprophylaxis therapy in patients with below-knee cast immobilization are still unclear, this study was designed to investigate the effect of aspirin and enoxaparin on the prevention of deep venous thrombosis in patients with an ankle sprain and cast immobilization.

\section{Patients and Methods}

\section{Study Patients}

Patients aged $\geq 15$ years, with nonsurgical, unilateral ankle sprains grade 2 and 3 who need rigid immobilization (e.g., by plaster cast) for at least 21 days and up to 30 days from March 2018 to February 2019, were enrolled in the study. The exclusion criteria included ankle instability, single or multiple fractures, history of anticoagulant therapy, previous active or currently treated peptic ulcer disease, pregnancy, breastfeeding, history of stroke in last year, under chronic treatment with other NSAIDs, risk factors of VTE, including body mass index $>30 \mathrm{~kg} /$ $\mathrm{m}^{2}$, estrogen-containing hormone replacement therapy or oral contraception, active cancer, VTE history, and congenital or acquired hypercoagulable state $[11,18,33]$.

According to the prevalence of venous thrombosis in the Testroote et al. study ( $4.3 \%$ to $40 \%)$, the number of samples was calculated at least 21 persons per group (totaling 63 people) based on $\mathrm{n}=\left[\left(\mathrm{Z}_{\alpha / 2}+\mathrm{Z}_{\beta}\right)^{2} \times\{(\mathrm{p} 1\right.$ $(1-\mathrm{p} 1)+(\mathrm{p} 2(1-\mathrm{p} 2))\}] /(\mathrm{p} 1-\mathrm{p} 2)^{2}$ formula, with the power of $80 \%$ and $\alpha$ error of $5 \%$. However, with a $30 \%$ chance of loss, a sample size of 90 patients (30 patients per group) was determined in the study [12].

\section{Study design}

This research was a double-blind, randomized clinical trial study. All ankle sprains were treated by a short leg cast from the fibula's head to the metatarsophalangeal joint. Then, the patients were randomly assigned into three groups; 1) without prophylactic treatment (the control group), 2) enoxaparin sodium (Clexane) $40 \mathrm{mg} / \mathrm{d}$ subcutaneously for 3 weeks (the enoxaparin group), and 3) Aspirin $325 \mathrm{mg} / \mathrm{d}$ for 3 weeks (the ASA group). The face-to-face visit was scheduled for the $1^{\text {st }}, 15^{\text {th }}$, and $30^{\text {th }}$ day of study. Non-weight bearing ambulation with crutches was maintained during the first 3 days. Full weight-bearing was initiated when patients could walk on various surfaces and up and downstairs with minimal discomfort. All patient's essential data such as age, gender, height $(\mathrm{m})$, weight $(\mathrm{kg})$, past medical and drug history, history of smoking, and thrombosis history were recorded. The patients were informed about the signs and symptoms of venous thrombosis and drug side effects at the beginning of treatment.

Serum D-dimer level was measured on the $1^{\text {st }}$ and $13^{\text {th }}$ day of study. The D-dimer level of greater than $0.2 \mu \mathrm{g} /$ $\mathrm{mL}$ has been considered a positive result. All patients underwent bilateral lower-limb Complete Compression 


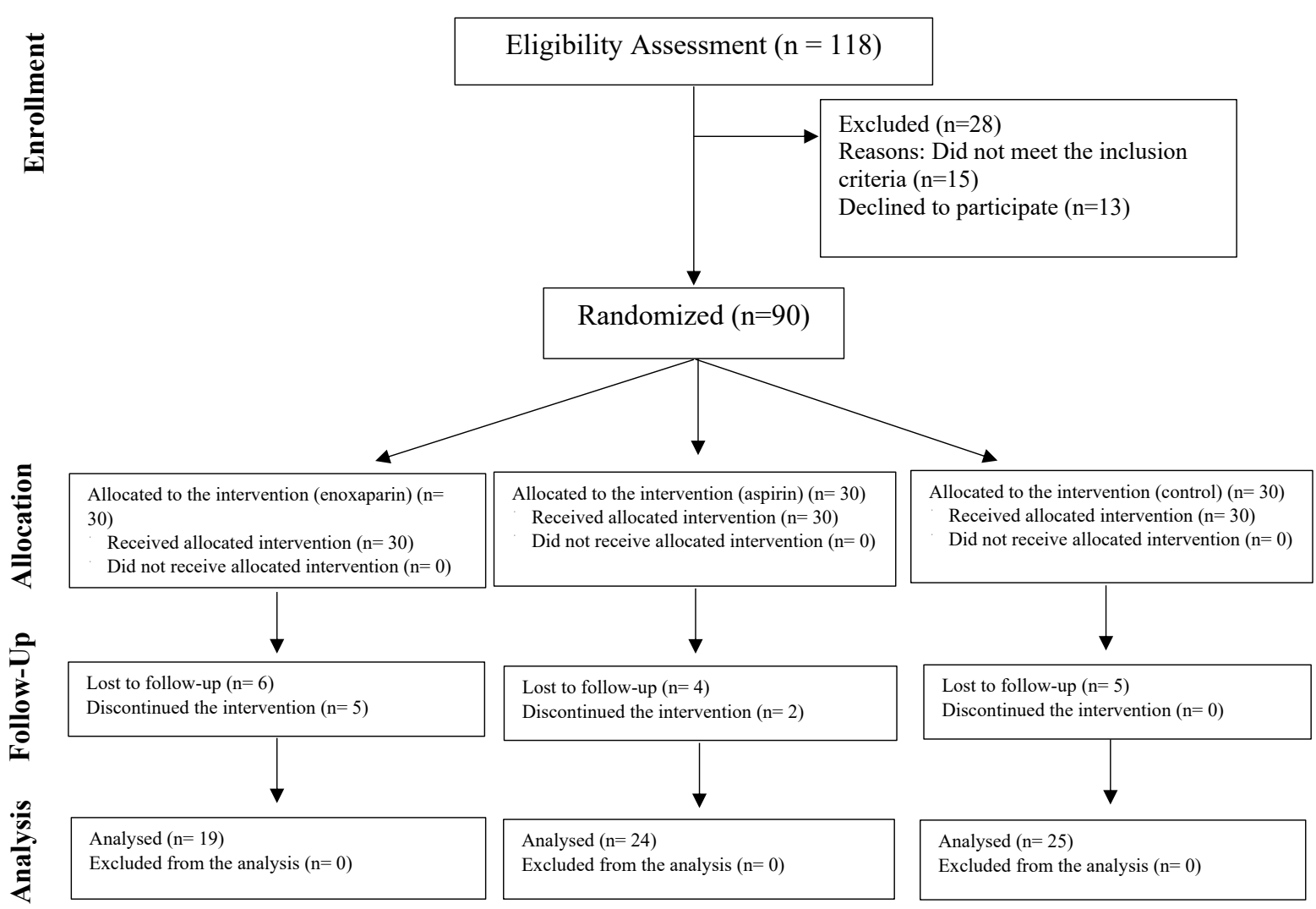

Figure 1. Study consort flowchart

Orthopedic Science

Ultrasonography (CCUS) and color Doppler ultrasonography after cast removal. Besides, whenever the patients got symptomatic, the D-dimer level was checked, and bilateral lower-limb CCUS and color Doppler ultrasonography were done. Also, appropriate confirmation diagnostic tests were performed for suspected Pulmonary Embolism (PE).

The study was conducted according to the ethical principles of the Declaration of Helsinki. The protocol was approved by the Ethics Committee of Mazandaran University of Medical Sciences and the Iranian Registry of Clinical Trials (IRCTID: IRCT20120726010405N5). Before the start of the study, all patients signed informed consent.

\section{Statistical analysis}

The obtained data were analyzed by SPSS v. 20. The quantitative data were expressed as mean and standard deviation and compared by t-test. The qualitative data were expressed as a percentage and compared by the Chi-squared test (if needed Fisher exact-test). Also, the Relative Risk (RR) was calculated with $95 \%$ confidence intervals $(95 \% \mathrm{CI})$. The P-values less than 0.05 were considered a statistically significant level.

\section{Results}

Of 118 patients with an ankle sprain, 90 patients were enrolled based on the inclusion and exclusion criteria and randomly assigned to one of the three groups (control, ASA, or enoxaparin). Five patients in the control group, 4 patients in the ASA group, and 6 patients in the enoxaparin group were excluded from the study because of their reluctance to continue the research. Furthermore, 2 patients in the ASA group and 5 patients in the enoxaparin group were excluded from the study due to discontinuation of the medication. Finally, data of 25 patients in the control group, 24 patients in the ASA group, and 19 patients in the enoxaparin group were analyzed (Figure 1).

The sex and age were not significantly different between the control and ASA groups $(\mathrm{P}=0.666$ and $\mathrm{P}=0.981$, respectively). However, in both control and ASA groups, the number of men was significantly greater than that in the enoxaparin group $(\mathrm{P}=0.002$ and $\mathrm{P}=0.001$, respectively). Also, the age of the enoxaparin group was significantly higher than the control and ASA group $(\mathrm{P}<0.001$ 
Table 1. Initial patient data based on their groups

\begin{tabular}{|c|c|c|c|c|}
\hline Patients Data & Control Group & ASA Group & Enoxaparin Group & $\mathbf{P}$ \\
\hline \multirow[t]{2}{*}{ Female No. (\%) } & $13(52)$ & $11(45.8)$ & $18(94.7)$ & \\
\hline & & & & 0.002 \\
\hline Male No. (\%) & $12(48)$ & $13(54.2)$ & $1(5.3)$ & \\
\hline Age, Mean $\pm S D(y)$ & $34.24 \pm 11.15$ & $34.16 \pm 10.31$ & $48.36 \pm 7.74$ & $<0.001$ \\
\hline Weight, Mean $\pm S D(k g)$ & $73.12 \pm 8.76$ & $71.83 \pm 9.08$ & $69.89 \pm 4.62$ & 0.417 \\
\hline Height, Mean $\pm S D(\mathrm{~cm})$ & $172.88 \pm 6.80$ & $173.04 \pm 6.12$ & $166.84 \pm 3.51$ & 0.001 \\
\hline $\mathrm{BMI}$, Mean $\pm \mathrm{SD}\left(\mathrm{kg} / \mathrm{m}^{2}\right)$ & $24.23 \pm 2.13$ & $23.73 \pm 2.06$ & $25.33 \pm 2.07$ & 0.048 \\
\hline History of heart disease No. (\%) & 0 & $1(4.2)$ & 0 & 0.394 \\
\hline Smoking No. (\%) & $2(8)$ & 0 & $1(5.3 \%)$ & 0.386 \\
\hline Injury to visit time (h) Mean \pm SD & $4.00 \pm 1.22$ & $4.25 \pm 2.28$ & $4.73 \pm 1.79$ & 0.411 \\
\hline
\end{tabular}

Table 2. Comparison of the outcomes of patients

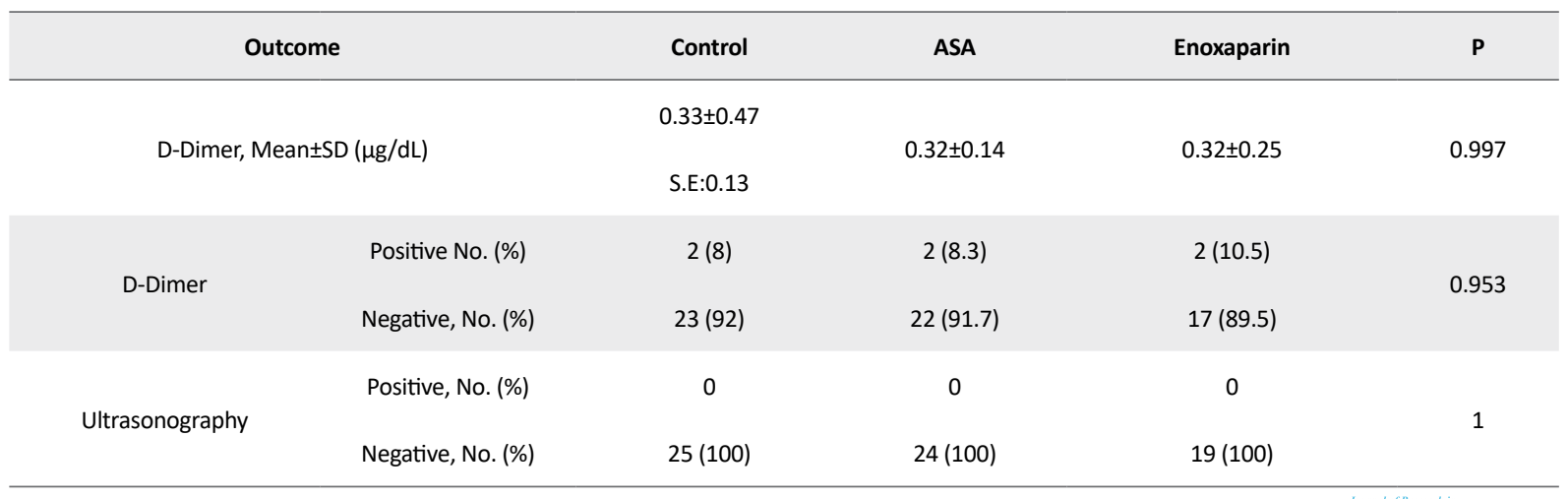

Orthopedic Science

VTE: Venous Thromboembolism; DVT: Deep Venous Thrombosis; ASA: Acetylsalicylic Acid; CCUS: Complete Compression Ultrasonography; VTE: Venous Thromboembolism; LMWH: Low Molecular Weight Heparin; HIT: Heparin-Induced Thrombocytopenia; NSAID: Nonsteroidal Anti-inflammatory Drug; PE: Pulmonary Embolism; IRCTID: Iranian Registry of Clinical Trials; RR: Relative Risk/Risk Ratio; CI: Confidence Intervals; BMI: Body Mass Index.

and $\mathrm{P}<0.001$, respectively). The history of heart disease $(\mathrm{P}>0.05)$, smoking $(\mathrm{P}>0.05)$, OCP $(\mathrm{P}>0.05)$, and the time between injury and referral to the hospital $(\mathrm{P}>0.05)$ were not significantly different between the three groups. The Body Mass Index (BMI) of the control and ASA patients and the control and enoxaparin groups were not statistically significant $(\mathrm{P}=0.401$ and $\mathrm{P}=0.096$, respectively). But the BMI of the patients in the enoxaparin group was significantly higher than that in the ASA group $(\mathrm{P}=0.016)$ (Table 1$)$.

No symptomatic patient was observed during the study. There was no statistically significant difference between the 3 groups regarding the mean $\mathrm{D}$-dimer level of patients at the end of the study $(\mathrm{P}>0.05)$. Relative risk was similar (Aspirin $\mathrm{RR}=1.04,95 \% \mathrm{CI}$ : $0.15-6.18$ vs enoxa- parin $\mathrm{RR}=1.31,95 \% \mathrm{CI}$ : 0.203-8.51). The results of CCUS and color Doppler ultrasonography of all patients were normal (Aspirin RR=1.04, 95\%CI: 0.21-50.43 vs enoxaparin $\mathrm{RR}=1.33$, 95\%CI: 0.027-64.05) (Table 2).

\section{Discussion}

Various risk factors for VTE are listed, including environmental and genetic factors [34, 35]. One of these risk factors is cast immobilization, especially in the lower extremity $[12,13]$. However, there is no consensus on prophylactic treatment and the type of prophylaxis [4]. So, we investigated the effect of aspirin and enoxaparin on the prevention of VTE in patients with an ankle sprain and below-knee cast immobilization. 
In this study, only 6 patients ( 2 patients in each group) had abnormal D-dimer status. There was no difference between the groups in the positivity of the D-dimer test. However, ultrasonography was normal, and VTE was not observed in this study. In patients who were treated with below-knee cast immobilization, various numbers have been reported to show the incidence of VTE. Rasi et al. investigated the incidence of Deep Venous Thrombosis (DVT) in subclinical immobility and the need for drug prophylaxis in patients with an ankle sprain or stable ankle fracture. In this study, 95 patients had $22.1 \%$ positive D-dimer levels (higher than $0.2 \mu \mathrm{g} / \mathrm{mL}$ ), and DVT was confirmed only in $3.1 \%$ of patients based on Doppler ultrasonography [36]. Shibuya et al. reported the incidence of DVT and pulmonary embolism in patients with foot and ankle trauma of $0.28 \%$ and $0.21 \%$, respectively [37]. These results showed the incidence of VTE was low in ankle injury, especially in an ankle sprain.

There is no consensus on the treatment of anticoagulant prophylaxis in patients with ankle sprain who treated with below-knee cast immobilization. Van Straien et al. believed that the incidence of DVT in patients with lower extremity injury was significantly higher than that in the control group, and given that the prevalence of lower extremity injury is high, it can be an essential factor in the occurrence of venous thrombosis and probably needs prophylactic treatment [38]. Similarly, Samama et al. compared the effect of fondaparinux with LMWH in preventing thromboembolism in patients with a belowknee injury who were treated non-surgically.

The incidence of VTE in fondaparinux (nadroparin) patients was $2.6(8.2 \%)$. They suggested that fondaparinux at a dosage of $2.5 \mathrm{mg} / \mathrm{d}$ could be more suitable than nadroparin for VTE prevention after below-knee injury with long-time immobilization [11]. Also, in 2018, Hickey et al. reviewed the effect of LMWH on the prevention of DVT in the ankle and below-knee injury and stated that LMWH would protect against DVT [22]. However, Patil et al. [7], Shibuya et al. [37], and Rasi et al. [36], similar to the present study, believed that DVT in below-knee cast immobilization was not a common complication and drug prophylaxis in these patients is unnecessary and has a huge economic burden on the health system.

According to the results of these studies, the incidence of VTE in ankle injuries, especially ankle sprain, is far less than other lower extremity injuries. However confounding effect of sex and BMI must be considered as the groups were not matched in the present study. Post hoc power analysis showed limited power because the incidence of venous thromboembolism was lower than expected, although this incidence is in line with other similar studies [12, 21-25]. It is considered a limitation of the present study. Another limitation was the short time of follow-up due to lack of compliance, so further studies with a bigger sample size and longer follow-up period are recommended.

\section{Conclusion}

Regarding the absence of VTE incidence during our 30 days follow-up period in this study, it seems that the use of prophylactic drugs such as aspirin or enoxaparin does not appear to be necessary for patients with an ankle sprain that requires long-term below-knee cast immobilization. Further studies with larger sample size and longer follow-up periods are recommended.

\section{Ethical Considerations}

\section{Compliance with ethical guidelines}

This study was conducted based in the ethical guidelines of the Declaration of Helsinki, 1975, and the Patients provided an informed written consent for information to be published

\section{Funding}

The present paper was based on a research proposal of authors supported by Mazandaran University of Medical Sciences.

\section{Authors' contributions}

Conceptualization: Mehran Razavipour; Methodology: Mehran Razavipour \& Salman Ghaffari; Investigation: Mehdi Mohebi; Data collection: Mehdi Mohebi \& Shayan Amjadi; Writing - original draft: Shayan Amjadi; Writing - review \& editing: Salman Ghaffarii; Supervision: Mehran Razavipour.

\section{Conflict of interest}

The authors declared no conflicts of interest.

\section{Acknowledgments}

The researchers thank the staff of the Orthopedic Ward of Imam Khomeini Hospital in Sari City for their help in the follow-up of the patients. 


\section{References}

[1] Leppilahti J, Orava S.Total Achilles tendon rupture. Sports Med. 1998; 25(2):79-100. [DOI:10.2165/00007256199825020-00002] [PMID]

[2] Galanaud JP, Sevestre-Pietri MA, Bosson JL, Laroche JP, Righini M, Brisot D, et al. Comparative study on risk factors and early outcome of symptomatic distal versus proximal deep vein thrombosis: Results from the OPTIMEV study. Thromb Haemost. 2009; 102(3):493-500. [DOI:10.1160/ TH09-01-0053] [PMID]

[3] Spencer FA, Emery C, Joffe SW, Pacifico L, Lessard D, Reed $\mathrm{G}$, et al. Incidence rates, clinical profile, and outcomes of patients with venous thromboembolism. The Worcester VTE study. J Thromb Thrombolysis. 2009; 28(4):401. [DOI:10.1007/s11239-009-0378-3] [PMID] [PMCID]

[4] Van Adrichem RA, Debeij J, Nelissen RG, Schipper IB, Rosendaal FR, Cannegieter SC. Below-knee cast immobilization and the risk of venous thrombosis: Results from a large population-based case-control study. J Thromb Haemost. 2014; 12(9):1461-9. [DOI:10.1111/jth.12655] [PMID]

[5] Goldhaber SZ, Bounameaux H. Pulmonary embolism and deep vein thrombosis. Lancet. 2012; 379(9828):1835-46. [DOI:10.1016/S0140-6736 (11)61904-1] [PMID]

[6] Kearon C, Akl EA, Comerota AJ, Prandoni P, Bounameaux $\mathrm{H}$, Goldhaber SZ, et al. Antithrombotic therapy for VTE disease: Antithrombotic therapy and prevention of thrombosis: American College of Chest Physicians evidence-based clinical practice guidelines. Chest. 2012; 141(suppl 2):e419Se496S. [DOI:10.1378/chest.11-2301] [PMID] [PMCID]

[7] Patil S, Gandhi J, Curzon I, Hui AC. Incidence of deep-vein thrombosis in patients with fractures of the ankle treated in a plaster cast. J Bone Joint Surg Br. 2007; 89(10):1340-3. [DOI:10.1302/0301-620X.89B10.19241] [PMID]

[8] Batra S, Kurup H, Gul A, Andrew JG. Thromboprophylaxis following cast immobilization for lower limb injuriessurvey of current practice in United Kingdom. Injury. 2006; 37(9):813-7. [DOI:10.1016/j.injury.2006.03.016] [PMID]

[9] Ho E, Omari A. Prevalence of acute deep vein thrombosis in patients with ankle and foot fractures treated with nonoperative management-a pilot study. Int J Angiol. 2017; 26(1):53-9. [DOI:10.1378/chest.11-2404] [PMID]

[10] Falck-Ytter Y, Francis CW, Johanson NA, Curley C, Dahl OE, Schulman S, Ortel TL, Pauker SG, et al. Prevention of VTE in orthopedic surgery patients: Antithrombotic therapy and prevention of thrombosis: American College of Chest Physicians evidence-based clinical practice guidelines. Chest. 2012; 141 (suppl 2):e278S-e325S. [DOI:10.1378/ chest.11-2404] [PMID] [PMCID]

[11] Samama CM, Lecoules N, Kierzek G, Claessens YE, Riou B, Rosencher N, et al. Comparison of fondaparinux with low molecular weight heparin for venous thromboembolism prevention in patients requiring rigid or semi-rigid immobilization for isolated non-surgical below-knee injury. J Thromb Haemost. 2013; 11(10):1833-43. [DOI:10.1111/ jth.12395] [PMID]
[12] Testroote M, Stigter WA, Janssen L, Janzing HM. Low molecular weight heparin for prevention of venous thromboembolism in patients with lower-leg immobilization. Cochrane Database Syst Rev. 2014; (4):CD006681. [DOI:10.1002/14651858.CD006681.pub3] [PMID]

[13] Ettema HB, Kollen BJ, Verheyen CC, Büller HR. Prevention of venous thromboembolism in patients with immobilization of the lower extremities: A meta-analysis of randomized controlled trials. J Thromb Haemost. 2008; 6(7):1093-8. [DOI:10.1111/j.1538-7836.2008.02984.x] [PMID]

[14] Baglin T, Barrowcliffe TW, Cohen A, Greaves M, British Committee for Standards in Haematology. Guidelines on the use and monitoring of heparin. Br J Haematol. 2006; 133(1):1934. [DOI:10.1111/j.1365-2141.2005.05953.x] [PMID]

[15] Nokes TJ, Keenan J. Thromboprophylaxis in patients with lower limb immobilisation-review of current status. Br J Haematol. 2009; 146(4):361-8. [DOI:10.1111/j.13652141.2009.07737.x] [PMID]

[16] Samama CM, Gafsou B, Jeandel T, Laporte S, Steib A, Marret $\mathrm{E}$, et al. [French Society of Anaesthesia and Intensive Care. Guidelines on perioperative venous thromboembolism prophylaxis. Update 2011. Short text (French)]. Ann Fr Anesth Reanim. 2011; 3 (12):947-51. [PMID] [DOI:10.1111/ j.1365-2141.2009.07737.x]

[17] Horner D. Towards evidence-based emergency medicine: Best BETs from the Manchester Royal Infirmary. Evidence exists to guide thromboembolic prophylaxis in ambulatory patients with temporary lower limb immobilization. Emerg Med J. 2011; 28(8):718-20. [DOI:10.1136/ emermed-2011-200396-3] [PMID]

[18] Samama CM, Albaladejo P, Benhamou D, Bertin-Maghit $\mathrm{M}$, Bruder N, Doublet JD, et al. Venous thromboembolism prevention in surgery and obstetrics: Clinical practice guidelines. Eur J Anaesthesiol. 2006; 23(2):95-116. [DOI:10.1017/ S0265021505002164] [PMID]

[19] Randelli F, Romanini E, Biggi F, Danelli G, Della Rocca G, Laurora NR, et al. II Italian intersociety consensus statement on antithrombotic prophylaxis in orthopaedics and traumatology: arthroscopy, traumatology, leg immobilization, minor orthopaedic procedures and spine surgery. J Orthop Traumatol. 2013; 14(1):1-13. [DOI:10.1007/s10195-0120214-y] [PMID] [PMCID]

[20] Riou B, Rothmann C, Lecoules N, Bouvat E, Bosson JL, Ravaud $\mathrm{P}$, et al. Incidence and risk factors for venous thromboembolism in patients with nonsurgical isolated lower limb injuries. Am J Emerg Med. 2007; 25 (5):502-8. [DOI:10.1016/j.ajem.2006.09.012] [PMID]

[21] Testroote M, Morrenhof W, Janzing H. Prevention of Venous Thromboembolism in Patients with Below-knee Immobilisation of the Leg-survey of Current Practice in the Netherlands. Acta Chir Belg. 2011; 111(1):32-5. [DOI:10.1080 /00015458.2011.11680700] [PMID]

[22] Hickey BA, Watson U, Cleves A, Alikhan R, Pugh N, Nokes $\mathrm{L}$, et al. Does thromboprophylaxis reduce symptomatic venous thromboembolism in patients with below knee cast treatment for foot and ankle trauma? A systematic review and meta-analysis. Foot Ankle Surg. 2018; 24(1):19-27. [DOI:10.1016/j.fas.2016.06.005] [PMID]

[23] Patel A, Ogawa B, Charlton T, Thordarson D. Incidence of deep vein thrombosis and pulmonary embolism after Achil- 
les tendon rupture. Clin Orthop Relat Res. 2012; 470(1):270-4. [DOI:10.1007/s11999-011-2166-6] [PMID] [PMCID]

[24] Kocialkowski C, Bhosale A, Pillai A. Venous thromboembolism prophylaxis in patients immobilised in plaster casts. Clin Res Foot Ankle. 2016; 4(3):4-4. https://www.omicsonline.org/open-access/venous-thromboembolismprophylaxis-in-patients-immobilised-in-plaster-casts2329-910X-1000203.php?aid=79373

[25] Trialists' Collaboration A. Collaborative overview of randomised trials of antiplatelet therapy-III: Reduction in venous thrombosis and pulmonary embolism by antiplatelet prophylaxis among surgical and medical patients. Antiplatelet Trialists' Collaboration. BMJ. 1994; 308(6923):235-46. [DOI:10.1136/bmj.308.6923.235] [PMID]

[26] O’Brien J, Duncan H, Kirsh G, Allen V, King P, Hargraves $R$, et al. Prevention of pulmonary embolism and deep vein thrombosis with low dose aspirin: Pulmonary Embolism Prevention (PEP) trial. Lancet. 2000; 355(9212):1295-302. [DOI:10.1016/S0140-6736 (00)02110-3] [PMID]

[27] Trialists'Collaboration A. Collaborative meta-analysis of randomised trials of antiplatelet therapy for prevention of death, myocardial infarction, and stroke in highrisk patients. Bmj. 2002; 324(7329):71-86. [DOI:10.1136/ bmj.324.7329.71] [PMID] [PMCID]

[28] Becattini C, Agnelli G, Schenone A, Eichinger S, Bucherin E, Silingardi $M$, et al. Aspirin for preventing the recurrence of venous thromboembolism. N Engl J Med. 2012; 366(21):1959-67. [DOI:10.1056/NEJMoa1114238] [PMID]

[29] Snyder MA, Sympson AN, Scheuerman CM, Gregg JL, Hussain LR. Efficacy in deep vein thrombosis prevention with extended mechanical compression device therapy and prophylactic aspirin following total knee arthroplasty: A randomized control trial. J Arthroplasty. 2017; 32(5):1478-82. [DOI:10.1016/j.arth.2016.12.027] [PMID]

[30] David Kaye I, Patel DN, Strauss EJ, Alaia MJ, Garofolo G, Martinez A, et al. Prevention of venous thromboembolism after arthroscopic Knee surgery in a low-risk population with the use of aspirin: A randomized trial. Bull Hosp Jt Dis. 2015; 73(4):243-8. [PMID]

[31] An VV, Phan K, Levy YD, Bruce WJ. Aspirin as thromboprophylaxis in hip and knee arthroplasty: A systematic review and meta-analysis. J Arthroplasty. 2016; 31(11):2608-16. [DOI:10.1056/NEJMoa1210384] [PMID]

[32] Brighton TA, Eikelboom JW, Mann K, Mister R, Gallus A, Ockelford $\mathrm{P}$, et al. Low-dose aspirin for preventing recurrent venous thromboembolism. N Engl J Med. 2012; 367(21):197987. [DOI:10.1056/NEJMoa1210384] [PMID]

[33] Kock H, Schmit-Neuerburg K, Hanke J, Rudofsky G. Thromboprophylaxis with low-molecular-weight heparin in outpatients with plaster-cast immobilisation of the leg. Lancet. 1995; 346(8973):459-61. [DOI:10.1016/S0140-6736 (95)91320-3] [PMID]

[34] Kyrle PA, Eichinger S. Deep vein thrombosis. Lancet. 2005, 365(9465):1163-74. [DOI:10.1016/S0140-6736 (05)71880-8]

[35] Rosendaal FR. Venous thrombosis: A multicausal disease Lancet. 1999; 353(9159):1167-73. [DOI:10.1016/S0140-6736 (98)10266-0]
[36] Rasi AM, Kazemian G, Moghadam ME, Larestani RT, Fallahi A, Nemati A, et al. Deep vein thrombosis following below knee immobilization: The need for chemoprophylaxis. Trau Trauma Mon. 2013; 17(4):367. [DOI:10.5812/traumamon.9158] [PMID] [PMCID]

[37] Shibuya N, Frost CH, Campbell JD, Davis ML, Jupiter DC. Incidence of acute deep vein thrombosis and pulmonary embolism in foot and ankle trauma: Analysis of the National Trauma Data Bank. J Foot Ankle Surg. 2012; 51(1):63-8. [DOI:10.1053/j.jfas.2011.10.017] [PMID]

[38] van Stralen KJ, Rosendaal FR, Doggen CJ. Minor injuries as a risk factor for venous thrombosis. Arch Intern Med. 2008; 168(1):21-6. [DOI:10.1001/archinternmed.2007.5] [PMID] 
This Page Intentionally Left Blank 